\title{
VIOLÊNCIA, MULHERES E ATENDIMENTO PSICOLÓGICO NA AMAZÔNIA E NO DISTRITO FEDERAL ${ }^{1}$
}

\author{
Madge Porto* \\ Júlia S. N. F Bucher-Maluschke
}

\begin{abstract}
RESUMO. O objetivo desse estudo é conhecer como os psicólogos/as entendem questões referentes à identificação da violência contra as mulheres nos atendimentos que realizam e como explicam as motivações para que algumas delas permaneçam em relações mediadas pela violência. $\mathrm{O}$ estudo é de caráter exploratório, descritivo e qualitativo, e para a coleta de dados utilizou-se a internet. Foram obtidos 24 questionários online de psicólogos/as inscritos/as no CRP 01. Foi constatado que estes/as identificam a violência principalmente quando expressada verbalmente pela mulher agredida e que apenas duas utilizam instrumento especifico de identificação desse tipo de experiência chamado screening. Foram apontadas como as principais causas de algumas mulheres permanecerem em situações de violência as dependências econômica e emocional e ainda os ganhos secundários que elas poderiam obter nessas relações. Conclui-se que se faz necessário aprofundar os estudos sobre o papel dos psicólogos e da psicologia clínica no contexto da violência contra as mulheres.
\end{abstract}

Palavras-chave: Violência contra as mulheres; atendimento psicológico; psicólogos.

\section{VIOLENCE, WOMEN AND PSYCHOLOGICAL CARE IN THE AMAZONIA AND THE DISTRITO FEDERAL}

\begin{abstract}
The aim of this study is to know how psychologists understand issues relating to the identification of violence against women in the care they undertake and how to explain the motivations for some of them remain in relationships mediated by violence. This is an exploratory, descriptive, qualitative study that used the Internet for data collection. We obtained 24 questionnaires online from psychologists enrolled in CRP 01. It was found that they identify violence especially when expressed verbally by the battered woman and that only two use specific instrument for the identification of this type of experience called "routine screening". It has been identified as major determinants for the permanence of some women in violent situations, the economic and emotional dependencies, as well as secondary gains they could obtain from these relations. We conclude that it is necessary to deepen the studies on the role of psychologists and clinical psychology in the context of violence against women.
\end{abstract}

Key words: Violence against women; psychological practices; psychologists.

\section{LA VIOLENCIA, LAS MUJERES Y LA ATENCIÓN PSICOLÓGICA EN EL AMAZONIA Y EL DISTRITO FEDERAL}

RESUMEN. El objetivo de este estudio es conocer cómo los psicólogos comprender las cuestiones relativas a la identificación de la violencia contra las mujeres en el cuidado que llevan a cabo y la manera de explicar las motivaciones de algunos de ellos permanece en las relaciones mediadas por la violencia. Se trata de un estudio exploratorio, descriptivo y cualitativo que utiliza la Internet para la recopilación de datos. Se obtuvieron 24 cuestionarios en línea psicólogos inscritos en el CRP 01. Se encontró que identifican la violencia, especialmente cuando se expresa verbalmente por la mujer maltratada y sólo dos psicólogos utilizan un instrumento específico para la identificación de este tipo de experiencia - revisión de rutina. Sido identificados como los principales factores determinantes para la permanencia de algunas mujeres en situaciones de violencia, las dependencias económicas y emocionales, así como ganancias secundarias que podrían obtener estas relaciones. Llegamos a la conclusión de que es necesario profundizar los estudios sobre el papel de los psicólogos y la psicología clínica en el contexto de la violencia contra las mujeres.

Palabras-clave: Violencia contra las mujeres; prácticas psicológicas; psicólogos.

\footnotetext{
Apoio: CNPq.

Psicóloga, Mestra em Saúde Coletiva pela Universidade Federal de Pernambuco e Doutoranda em Psicologia Clínica e Cultura pela Universidade Brasília. Bolsista de Doutorado do CNPq. Psicóloga Clínica da Universidade Federal do Acre, Brasil.

\# Psicóloga, Doutora em Ciências da Família e Sexologia pela Universidade de Louvain/Bélgica, com pós-doutorado em Psicologia Clínica (Terapia Familiar) na Universidade de Tübingen/Alemanha. Professora Emérita e Pesquisadora colaboradora na Universidade de Brasília, Brasil.
} 
As políticas públicas promovidas pelo Governo Federal através da Secretaria de Políticas para as Mulheres - SPM apresentam várias ações, entre elas as políticas para o enfrentamento à violência contra as mulheres. Nestas políticas há uma demanda explícita pelo trabalho de um profissional de Psicologia, porém essa demanda apresenta uma contradição: há uma expectativa de que a intervenção psicológica promova mudanças na vida das mulheres que sofrem violência, contudo as orientações apresentadas nos manuais dos serviços que atendem essas mulheres tendem para uma intervenção indiferenciada dos profissionais da equipe multidisciplinar (Brasil, 2003, 2005a e b, 2006).

Este estudo justifica-se principalmente pelo fato de o atendimento psicológico aparecer como uma das intervenções relevantes dentro das políticas públicas de enfrentamento à violência contra as mulheres. Existe a preocupação em garantir à mulher um acolhimento especializado de forma a não apenas recebê-la, mas também ajudá-la a mudar sua vida, e nesse ponto é que se busca a atuação do profissional de Psicologia.

A atuação dos/as psicólogos/as ganha destaque também diante da queixa recorrente nas instituições e nos serviços especializados de atendimento às mulheres que vivem em situação de violência delegacias especializadas, casas-abrigo, centros de referência e unidades de saúde - de que a intervenção é difícil ou o atendimento não muda a situação vivenciada por um número significativo dessas mulheres (Meneghel, Camargo, Fasolo, Mattiello, Silva, Santos, Dagord, A. L., Reck, A., Zanetti, L., Sottili, M., \& Teixeira, 2000; Garcia, Ribeiro, Jorge, Pereira, \& Resende, 2008). O motivo disto é que as mulheres desistem de prosseguir na responsabilização judicial do agressor ou reclamam da situação em que vivem, mas continuam no relacionamento.

Nesse contexto, a expectativa é que a Psicologia tenha como responder a essas questões. Porém as eventuais dificuldades para o(a) psicólogo(a) realizar essa expectativa não são consideradas, além de não existir um trabalho efetivo de apoio ao(à) psicólogo(a) que trabalha com essas populações. Por fim, também foi observado que são escassos os estudos sobre esse tema.

Diante desse quadro, o objetivo deste estudo é investigar como os(as) psicólogos(as) identificam situações de violência nos atendimentos que realizam e qual o entendimento que têm sobre a permanência de algumas mulheres em relações mediadas pela violência. Para isso foi enviado um questionário online aos(às) psicólogos(as) inscritos no Conselho Regional de Psicologia $1^{a}$ Região - CRP 01 que têm acesso à rede mundial de computadores.

\section{O ATENDIMENTO PSICOLÓGICO E AS MULHERES EM SITUAÇÃO DE VIOLÊNCIA.}

Algumas experiências de atendimento psicológico às mulheres em situação de violência mostram as potencialidades do trabalho com o psiquismo, principalmente quando a equipe multiprofissional depara-se com mulheres que após o acesso às políticas de proteção decidem voltar a conviver com o marido agressor, embora sua vida e a de seus filhos sejam submetidas a riscos e elas sofram agressões físicas, sexuais e verbais (Francisquetti, 2005; Garcia et al., 2008). Como violência contra as mulheres são entendidos aqui os vários tipos de violência que atingem as mulheres pelo fato de serem mulheres. Violência contra as mulheres é um termo cunhado pelo movimento feminista que diz respeito às desigualdades na relação entre mulheres e homens (Brandão, 1998). Deparar-se com essas situações leva à percepção de que a violência contra as mulheres se dá em um “... contexto complexo, onde estão em jogo, atravessando as pessoas em cena, a realidade externa, a cultura, os fluxos, as forças inconscientes, fantasias, traumas, desejos de vida, desejos de destruição morte..." (Francisquetti, 2005, p. 02).

Por outro lado, segundo Machado (2004), o atendimento psicológico às mulheres vítimas de violência promove no(a) terapeuta/psicoterapeuta/psicólogo(a) dilemas teóricos, técnicos e emocionais. Entre esses últimos, para a autora, estão o estresse pós-traumático dos terapeutas que trabalham com essas mulheres, a "vitimização por contato" (Machado, p. 407) e o aumento do risco da síndrome de burnout, decorrente da falta de supervisão e de uma rede de suporte.

A discussão do fenômeno da violência contra as mulheres, dentro dos estudos feministas, apresenta uma construção cultural do lugar da mulher na sociedade, em especial nas sociedades patriarcais, em que elas são marcadas por uma posição de submissão, de assujeitamento. A violência, assim, aparece como forma de disciplinar e controlar. Dessa forma, nas situações de violência contra as mulheres não haveria um homem que fosse agressor por ser doente, portador de um transtorno psíquico, ou seja, um homem que matasse ou espancasse uma mulher por não se controlar como um homem "normal". Também, dentro dessa perspectiva, não haveria uma mulher que se submetesse à violência por, necessariamente, ser 
portadora de transtorno mental, como o masoquismo ou a melancolia - este entendido por Freud como algo que se constitui da fusão de duas pulsões, de forma que a sexualidade se une a uma destrutividade direcionada para dentro (Freud, 1930/2010, 1924/2007), e a melancolia como “... um estado de ânimo profundamente doloroso, por uma suspensão do interesse pelo mundo externo, pela perda da capacidade de amar, pela inibição geral das capacidades de realizar tarefas e pela depreciação do sentimento de si" (Freud, 1917/2006, p.103-104).

Haveria, no caso da violência contra as mulheres, uma sociedade que estabelece/determina relações de poder assimétricas, hierarquizadas entre os sexos que, assim, determinariam as desigualdades a partir das diferenças sexuais. Existem homens que batem nas mulheres com as quais estabelecem relações afetivosexuais por sentirem-se com esse poder e existem as mulheres que se submetem porque esse seria seu papel dentro das sociedades de formação patriarcal.

No momento em que as mulheres tomassem consciência de sua submissão e os determinantes desta, esse quadro mudaria e as mulheres não mais estariam submissas às violências impostas por seus cônjuges, por seus companheiros ou quaisquer outros homens de sua convivência afetiva e familiar. Quando compreendessem que do mesmo jeito que foi construído um papel subalterno para as mulheres na sociedade, esse poderia ser desconstruído para dar lugar a um papel de protagonista de suas vidas, de rompimento com a sujeição aos homens.

Essa explicação é importante e em grande parte satisfatória, contudo não responde às questões referentes às mulheres que, mesmo tendo a oportunidade de recorrer as políticas públicas especializadas para as mulheres em situação de violência e, nesses espaços, de refletir sobre sua condição, continuam vivendo submetidas à violência. Em muitos casos, mesmo correndo risco de morte e estando suas vidas em perigo, elas continuam a convivência marital, não rompem um relacionamento mediado pela violência.

Essa preocupação foi objeto da pesquisa de Oliveira (2004), que relata como justificativa de seu estudo a percepção da situação em que, apesar da reflexão sobre a opressão de gênero, algumas mulheres "escolhem" continuar vivendo em situação de violência.

O conceito Gênero é entendido aqui como uma categoria de análise que apresenta as diferenças entre homens e mulheres não como determinação biológica, e sim, como uma construção histórico-social que determina uma desigualdade de mulheres e homens no acesso ao poder na sociedade, justificada pelas diferenças físicas entre os sexos (Scott, 1990).

Oliveira (2004), que fez seu estudo depois de uma experiência como psicóloga num serviço para mulheres em situação de violência no Estado do Acre, destaca que tendia a pensar, dentro das discussões do grupo de trabalho, que a violência doméstica seria fruto dos valores culturais que oprimem as mulheres; todavia entrava em conflito com a sua perspectiva como profissional: "como psicóloga minha intervenção tendia a avaliar o papel delas nas relações violentas, o que necessariamente não era contraditório às explicações no viés de gênero..." (p. 20). Oliveira (2004) percebia que um grupo dessas mulheres não saía da relação mediada pela violência:

(...) uma intervenção orientada para desenvolver a consciência do lugar de oprimida gerava um avanço, mas parecia ainda a metade do caminho (...) na maioria das vezes não era o bastante para fazer com que a mulher saísse da relação conjugal violenta, mesmo que quisesse, que tivesse vontade/determinação (...) remetendo-me a analisar dificuldades "psicológicas", às vezes como consequência da violência recebida, mas por outras também, como geradora de violência. (Oliveira, 2004, p. 21).

No estudo empírico, que realizou posteriormente à experiência no Acre, Oliveira (2004) entrevistou três casais, com o objetivo de identificar a responsabilidade de ambos nas situações de violência e utilizou o conceito de "duplo vínculo", que para a autora "(...) se propõe a dar subsídios para a discussão de contextos comunicacionais e interacionais." (Oliveira, 2004, p. 72), para explicação do fenômeno. $\mathrm{Na}$ revisão teórica, a autora, embora sem se aprofundar, apresenta a psicanálise como teoria que precisa ser considerada no tocante à influência das dinâmicas intrapsíquicas e a conceitos como desejo e falta. Relaciona essas dinâmicas ao conceito de gênero para pensar a categoria "amor" no contexto da violência contra as mulheres, mais uma vez afirmando que considerar as questões da subjetividade não nega necessariamente as explicações a partir do conceito de gênero. Vale destacar que subjetividade aqui é entendida como: “(...) instâncias psicológicas que compõem este sujeito: o psiquismo, a cognição, a 'mente', a consciência, a identidade, o self; mas também, as percepções, as interpretações e certa dimensão "intrapsíquica" - das emoções, do desejo, do inconsciente" (Prado Filho \& Martins, 2007, p. 14).

Para Prado Filho e Martins (2007, p. 14), "sujeito nos domínios da psicologia implica falar da sua 
colocação como objeto para um discurso científico socialmente autorizado a enunciar verdades".

Assim, Oliveira (2004) propôs a escuta do casal que vive em situação de violência, pois tinha como hipótese que ambos viviam contradições, sofrimentos, sentimentos e pensamentos que, "psicopatológico ou não, estava ali” (Oliveira, p. 22).

O estudo de Oliveira (2004), como ela mesma diz, é um ponto de vista que pode não ser aceito, mas precisa ser considerado. É nessa perspectiva que este estudo se apresenta, tomando algumas dessas inquietações, mas destacando outro ponto de vista, a partir da experiência de psicólogos(as) que atendem às mulheres, e não dos casais que vivenciam a violência. Assim como Oliveira (2004), que propõe que a psicologia articule-se às teorias feministas, o objetivo deste artigo é contribuir com essa discussão a partir de uma perspectiva diferente da apresentada pela autora, que trabalha com as mulheres que sofrem violência e seus companheiros utilizando o conceito de "duplo vínculo". Aqui o objetivo é investigar, a partir do ponto de vista dos(as) psicólogos(as) que realizam atendimentos psicológicos a essas mulheres, como identificam as situações de violência e como entendem a permanência de algumas delas nessas situações, utilizando o método de Analise de Conteúdo (Bardin, 1977/1997).

Assim, podem-se destacar dois estudos referentes à prática de profissionais da psicologia que trabalham com mulheres em situação de violência. Porto (2006, 2008) apresenta os resultados de oferecer aos(às) psicólogos(as) que trabalham com mulheres em situação de violência um espaço para a discussão e troca de experiências clínicas e institucionais no contexto da violência contra a mulher em um município da Região Norte, o qual foi denominado Roda de Conversa em Psicologia. A participação assídua dos(as) psicólogos(as) numa atividade não obrigatória e a avaliação positiva do grupo ao final do trabalho apontam para a existência de uma inquietação desses profissionais que demanda atenção e investigação.

Hanada, D'Oliveira, Schraiber (2008, 2010) apresentam um estudo realizado em São Paulo - SP com o objetivo de identificar como a assistência psicológica é pensada e organizada nos serviços da Rede de Redução de Violência Contra a Mulher. Como resultado observou uma confusão entre o atendimento psicológico e o trabalho do assistente social e notou que, em muitos casos, o trabalho que o(a) psicólogo(a) realizava também era realizado por toda a equipe. Ao mesmo tempo, critica as intervenções para o empoderamento das mulheres, as quais, para as autoras, ficaram limitadas à dimensão individual: "Dessa maneira, novamente, o problema da violência de gênero pareceu tornar-se individualizado e psicologizado, com compreensão reduzida do trabalho do psicólogo na emancipação dessas mulheres..." (Hanada, D'Oliveira \& Schraiber, 2008, p. 06).

Esse estudo parece contraditório, pois, ao mesmo tempo em que identifica que a intervenção realizada pelos(as) psicólogos(as) dos serviços estudados é semelhante à dos outros integrantes da equipe, propõem que a intervenção clínica em psicologia seja realizada fora desses serviços. Assim se pode perguntar: para que ter um(a) psicólogo(a) na equipe se outro profissional faz até o que os(as) próprios(as) psicólogos(as) consideram como algo específico da psicologia? Como fazer uma intervenção especializada, específica, quando se espera que todos tenham o objetivo de conscientizar sobre a opressão de gênero a partir de um mesmo tipo de intervenção e de uma mesma teoria e as questões da subjetividade são avaliadas como necessariamente reducionistas?

As questões que motivaram este estudo também vêm desta inquietação: qual o papel do(a) psicólogo(a) nesses serviços? Será que focar as questões da subjetividade, da individualidade, necessariamente, nega o contexto e o entendimento da violência doméstica e de gênero como fenômeno sociocultural? Haveria a indicação de um trabalho em nível da subjetividade, individualidade, principalmente para o grupo que se mantém em situação de violência após as ações padrão dos serviços especializados? Não estaria aí o principal papel do(a) psicólogo(a)? Essas questões serão discutidas num estudo mais amplo a ser apresentado oportunamente. Neste artigo pretende-se apresentar o que psicólogos(as) que atendem mulheres em situação de violência pensam sobre esse fenômeno em dois pontos específicos: a forma como identificam a violência e como explicam a permanência de algumas mulheres nessas situações.

\section{MÉTODO}

A proposta metodológica foi de um estudo exploratório, descritivo e qualitativo. Isso se justifica pela escassez de referências bibliográficas que tratem especificamente do tema violência contra as mulheres $\mathrm{e}$ atendimento psicológico. A literatura tem apresentado há algum tempo a opção pelo uso da rede mundial de computadores como recurso de coleta de dados (Seymour, 2001). Alguns estudos mais amplos em psicologia têm utilizado esse recurso - por exemplo, Bastos \& Gondim (2010), que, juntamente 
com seus colaboradores, investigaram os(as) psicólogos(as) brasileiros(as), e o Centro de Referência Técnica em Psicologia e Políticas Púbicas - Crepop (Conselho Federal de Psicologia, 2008) que realizou vários estudos, entre eles uma investigação sobre os(as) psicólogos(as) que trabalhavam nas políticas públicas de enfrentamento à violência contra as mulheres. Ambos os estudos utilizaram o recurso da rede mundial de computadores para uma coleta eletrônica dos dados, com o objetivo de contatar os(as) psicólogos(as) inscritos no sistema Conselhos de Psicologia (CRPs e Conselho Federal de Psicologia CFP).

Gondim, Luna, Souza, Sobral \& Lima (2010), além do estudo quantitativo referente à identidade dos(as) psicólogos(as) brasileiros(as), fazem uma análise qualitativa na intenção de aprofundar a compreensão sobre a identidade desses(as) profissionais. Para isso realizaram onze entrevistas online por meio do recurso MSN (Messenger) do ambiente Windows, em que o contato inicial com os(as) possíveis entrevistandos(as) foi por endereço eletrônico ( $e$-mail).

Diante dessas experiências, decidimos realizar a coleta dos dados utilizando a rede mundial de computadores, pois assim poderíamos ter acesso às experiências de psicólogos(as) de estados da Região Norte que na época da coleta faziam parte da jurisdição do Conselho Regional de Psicologia $1^{\mathrm{a}}$ região - CRP 01 e agora fazem parte do CRP 20 (Conselho Federal de Psicologia, 2011).

No presente estudo, inicialmente, foi formulado um roteiro de entrevista que foi enviado por correio eletrônico, após um teste piloto (pré-teste). Nesse teste a mensagem eletrônica foi enviada a alguns(mas) psicólogos(as) que não são inscritos na área de jurisdição a que o estudo se restringe, para que respondessem e enviassem sua avaliação. $O$ instrumento foi dividido em três partes: uma para psicólogos(as) que já tinham atendido em algum momento mulheres em situação de violência, outra para os(as) que trabalham ou já trabalharam em serviços da rede de enfrentamento à violência contra as mulheres e uma terceira, comum aos dois grupos, para a definição de um perfil sociodemográfico e de formação em psicologia. $\mathrm{Na}$ parte inicial do questionário perguntava-se como identificou o caso de violência, qual a intervenção que realizou, se conhecia os documentos da Secretaria de Política para as Mulheres - SPM, como viveu essa experiência, quais as teorias indicadas para essa intervenção e como compreendia o fenômeno da violência contra as mulheres. Para os(as) psicólogos(as) que trabalham ou trabalharam nos serviços especializados foram acrescentadas questões sobre o resultado e a avaliação da eficácia, dificuldades e facilidades da intervenção e, por fim, sobre o papel que o psicólogo/a tem/teve na equipe multiprofissional.

$\mathrm{O}$ instrumento de coleta foi direcionado ao endereço eletrônico do Conselho Regional de Psicologia $1^{\mathrm{a}}$ Região, formado na época pelo do Distrito Federal sede das seções regionais de quatro estados da Região Norte - Acre, Amazonas, Rondônia e Roraima. O CRP 01, por sua vez, encaminhou-o para todos os(as) psicólogos(as) que tinham endereços eletrônicos cadastrados.

Após o retorno de vinte questionários decidimos utilizar um novo recurso para um segundo envio, também por meio do CRP 01, na tentativa de ampliar o número de questionários respondidos, além de acrescentar questões que complementassem algumas lacunas percebidas na primeira aplicação. Por fim obtivemos, ao todo, vinte e quatro questionários online - ou seja, somaram-se mais quatro aos vinte iniciais dos quais nove com as complementações solicitadas.

\section{Procedimento de análise}

No momento da análise identificamos um limite no questionário online, pois existe um limite de espaço para as respostas e isso não era percebido por quem enviava o questionário e inicialmente também não tínhamos identificado; porém isso não inviabilizou a coleta, pois os(as) voluntários(as) da pesquisa posteriormente enviaram as respostas que haviam gravado em programa de texto. Isso ajudou na organização dos dados que haviam sido atingidos pelo problema do programa utilizado.

Assim, depois de sanado o problema do instrumento, fizemos a análise de conteúdo conforme Bardin (1977/1997). Vale destacar que esse estudo faz parte de uma pesquisa mais ampla sobre o atendimento psicológico às mulheres em situação de violência e que nesse artigo serão apresentadas duas das categorias identificadas nos questionários analisados: como os(as) psicólogos(as) identificam a violência nos atendimentos que realizam e o que entendem sobre as motivações de algumas mulheres para permanecerem em relações mediadas pela violência.

\section{RESULTADOS E DISCUSSÃO}

Exporemos resultados de forma a inicialmente descrever as características dos(as) participantes do 
estudo e em seguida apresentar as categorias de análise propostas: as formas de identificação da violência nos atendimentos realizados e as explicações que os(as) informantes têm para a permanência de mulheres em relações mediadas pela violência, em outras palavras, o "que mantém a submissão feminina" (fala da informante 05).

\section{Caracterização dos(as) psicólogos(as) informantes}

Os resultados obtidos, no que se refere ao perfil sociodemográfico dos(as) voluntários(as) da pesquisa, são próximos dos encontrados no estudo de Bastos, Gondim e Rodrigues (2010), que também utilizaram a rede mundial de computadores como ferramenta de coleta de dados.

Identificamos que o grupo de vinte e quatro informantes se mantém, em alguns itens, próximo das características do grupo estudado por Bastos et al. (2010), que teve 3.335 informantes: a maioria dos(as) informantes são do sexo feminino $(83,3 \%$ em ambos os estudos), e a idade média é de 36,7 anos no estudo de Bastos et al. (2010), e no grupo estudado é de 35,7 anos. Com relação à faixa etária, no estudo de Bastos et al. (2010), 50\% dos(as) participantes tinham até 34 anos, e no estudo ora apresentado o percentual de participantes dessa faixa etária é $45,9 \%$.

Não se tem, com isso, o objetivo de discutir a significância estatística das diferenças percentuais encontradas, pois no caso deste estudo a proposta é uma pesquisa qualitativa, exploratória, descritiva, diferente da dos autores acima citados. O que se quer é apresentar que os(as) informantes que se dispuseram a participar da pesquisa formam um grupo com características próximas, em alguns itens, daquelas que Bastos et al. (2010) identificaram como perfil dos(as) psicólogos(as) brasileiros(as), principalmente no tocante à idade média e à distribuição do grupo por sexo; e é considerando esse dado que se podem apresentar as características dos(as) voluntários(as) do estudo.

Dos(as) vinte e quatro profissionais informantes, nove têm atuação no Distrito Federal e 15 ficaram distribuídos nas seções do Amazonas, Acre e Roraima. Foi identificado que o(a) psicólogo(a) mais jovem que respondeu ao questionário tinha 25 anos e o(a) mais velho(a), 48 anos. Dentro do quesito cor, tomando como referência a classificação do Instituto Brasileiro de Geografia e Estatística, a maioria se declarou de cor branca $(54,2 \%)$. No item religião $54,1 \%$ se apresentam como cristãos. Por fim, 50\% referem viver com parceiro. Não houve nenhum psicólogo(a) que se tivesse declarado filiado a um partido político e apenas três informaram participar em algum movimento social. Apenas duas informantes relataram possuir o título de especialista, que é emitido pelo Conselho Federal de Psicologia desde 2000 e regulamentado por uma portaria que foi substituída em 2007 (CFP, 2007).

Duas psicólogas referiram nunca ter atendido uma mulher em situação de violência, uma tinha nove anos de trabalho (informante 12) e outra, vinte anos de carreira (informante 07). Isso chama a atenção, pois, considerando-se que entre $28,9 \%$ e $36,9 \%$ das mulheres já sofreram violência física e/ou sexual (D'Oliveira, Schraiber, França-Júnior, Ludermir, Portella, Diniz, Couto, \& Valença, 2009) e que $76 \%$ as mulheres usuárias do serviço público de saúde relatam pelo menos um episódio de violência na vida (Schraiber, D’Oliveira, Couto, Hanada, Kiss, Durand, Puccia, \& Andrade, 2007), é de pensar se estas psicólogas de fato não atenderam ou se não identificaram a violência. Por sua vez, outra informante diz ter atendido mulheres em situação de violência em todas as áreas em que trabalhou: "já atendi mulheres em situação de violência em consultório como psicoterapeuta e em minha prática como psicóloga institucional, em instituições" (Informante 05).

\section{Identificação da violência}

Com relação à primeira categoria que se destacou e será apresentada nesse estudo, pode-se dizer que dos(as) vinte e quatro informantes, nove atendem ou já atenderam em serviços especializados (delegacia da mulher, centro de referência, casa-abrigo, vara de atendimento à mulher em situação de violência e serviço de abortamento previsto em lei), e informaram identificar a violência por meio do próprio relato das mulheres, da visualização de hematomas ou depois da utilização de instrumento específico para identificar violência, que uma chamou de "screening" (informante 24).

Os(as) psicólogos(as) que não atendiam em serviços especializados, mas informaram já ter atendido mulheres em situação de violência (treze ao todo) também afirmaram ter identificado ações de violência na procura pelo atendimento, quando a mulher expressa a queixa explicitamente em seu relato verbal. Afirma uma psicóloga: "Na verdade eu não identifiquei, ela procurou o serviço, para saber se poderia ajudá-la." (Informante 16). Outros(as) afirmaram que os atendimentos foram consequência dos encaminhamentos do Poder Judiciário ou de “(...) seus médicos devido a doenças psicossomáticas e com algum tempo de psicoterapia elas já conseguiam relatar episódios de violência conjugal que sofreram" 
(Informante 14). A informante 04 relata: "A mulher solicitou atendimento para tratar de uma depressão $e$ 'aumentar' sua autoestima. Ela contava os maustratos que sofria, física e emocionalmente”. Algo discutido já há algum tempo na literatura é que as mulheres procuram lidar indiretamente com a violência, buscando ajuda para os sintomas ou as consequências da violência (D'Oliveira \& Schraiber, 2000; Heise, Pitanguy \& Germain, 1994).

\section{O "que mantém a submissão feminina"}

Com relação à segunda categoria a ser apresentada, o grupo de informantes composto pelos(as) psicólogos(as) dos serviços especializados explicou que a permanência das mulheres em situação de violência decorre principalmente da dependência financeira, mas também da dependência emocional/afetiva, que eles(as) entendem como "sentimento pelo companheiro" (Informante 15) ou "envolvimento afetivo" (Informante 03). Uma psicóloga afirmou que a "mulher teme passar necessidades/dificuldades com os filhos" (Informante 18) e também referiu "falta de profissão, de escolaridade" (Informante 02).

As questões culturais, sociais e religiosas que pressionam as mulheres a permanecerem em situações de violência são apontadas como idealização do casamento e da maternidade: "ainda idealizam muito o casamento e a maternidade e acabam apostando tudo nesses objetivos e se responsabilizando sozinhas pelo sucesso ou fracasso destas instituições." (Informante 01).

A "autoestima prejudicada" (Informante 24) e também "a autoestima baixa, falta do amor próprio, a impossibilidade de se ver como uma mulher que não precisa se submeter a situações violentas" (Informante 03), foram também argumentos que se destacaram. Igualmente questões como "isolamento familiar e social, e sentimentos como medo [...] vergonha e culpa" (Informante 24) são apontadas como o que faz uma mulher permanecer em situação de violência. Segundo os(as) psicólogos(as), a mulher sente/entende que tem uma responsabilidade sobre o que ocorre, que há um merecimento: "que a culpa são delas mesmas e que sofrem porque merecem" (Informante 03).

Outras psicólogas destacam que as mulheres "alimentam a esperança de que o cônjuge pode mudar" (Informante 03) e - o pior - "acreditam que podem mudá-lo" (Informante 15). Nesse caso, o que determinaria tal concepção? Como poderiam elas mudar o comportamento, as atitudes, os sentimentos e os desejos do marido? Brandão (1998) já apontava que essa é uma tendência das mulheres: quando retiram a queixa nas delegacias da mulher elas se sentem mais fortes que eles, com mais condições de lidar com as dificuldades e com as emoções.

Outra questão aqui referida pelos(as) psicólogos(as) que atendem nos serviços especializados é que as mulheres "não entendiam como violência [...] por vezes não consideravam violência" (Informante 01), apresentando que há uma "naturalização do fenômeno da violência" (informante 24).

Por fim, destacam que também existe o medo caso tomem uma decisão de rompimento da relação, “(...) teme a reação do companheiro (...), pois muitos companheiros ameaçam dizendo que se a mulher não for deles, não será de mais ninguém" (Informante 18) e a existência de "problemas psíquicos" (Informante 24).

A informante 5 se inclui no grupo do qual fala mulheres que sofrem violência -, aqui talvez numa identificação da condição de mulher que por fazer parte dessa categoria também está sujeita às mesmas vivências das mulheres que atende: "Permanecemos submissas, com ou sem a explicitação dos mecanismos de dominação masculinos, quando nos consideramos incapazes de promover mudanças nas formas como nos relacionamos com os homens ou consideramos as mudanças como uma perda de identidade". Aqui ela destaca que ter consciência da submissão não é o suficiente, pois há algo que precisa mudar na forma como a mulher se percebe, o que supostamente demandaria um empoderamento não só político, como defendem Hanada et al. (2008, 2010), mas também interno, pessoal, da ordem da subjetividade, no sentido da "dimensão 'intrapsíquica', das emoções, do desejo, do inconsciente" (Prado Filho \& Martins, 2007, p. 14).

O grupo de psicólogos(as)) que não trabalham ou não trabalharam nos serviços especializados (quinze informantes - treze já citadas e duas que referem nunca ter atendido uma mulher em situação de violência) tem entendimento semelhante ao do grupo anterior no que se refere ao que poderia determinar a submissão de algumas mulheres à violência. A dependência econômica é citada por quase todos, "por não ter emprego ou alguma forma de prover financeiramente o lar" (Informante 13); todavia, foi interessante a fala da Informante 14, que inicia destacando a dependência econômico-financeira e termina na emocional:

"Houve casos em que a mulher se submetia por não ter renda para se manter fora daquela relação, mas com o tempo percebemos que 
ela já conseguira separar e viver até melhor financeiramente em outros momentos, que sua família dava apoio e suporte e ela sempre conseguia emprego quando queria, mas o que realmente a prendia era um laço invisível, uma homeostase, o lugar familiar, que alguns autores chamaram de dependência emocional."

Nessa perspectiva a informante continua: " $E$ uma dependência outra, uma tendência a manter-se no mesmo lugar de 'submissão', alvo de violência”. A informante prossegue: "Todavia, também esse alvo de violência' era relativo. Não era um lugar fixo e imutável, ao contrário, era usado por ela para violentar simbolicamente e psicologicamente ao marido e aos filhos". Esse aspecto é discutido por Oliveira (2004), a qual destaca que as mulheres sofreriam violência física, porém perpetrariam "mais violência psicológica" (Oliveira, 2004, p. 214), o que deu "... visibilidade às contradições das mulheres" (p. 194) e às contradições da "conjugalidade moderna" (p. 205) em que as mulheres tentariam contrapor-se às agressões vividas utilizando algum tipo de agressão.

A informante 19, também dentro da perspectiva de corresponsabilização das mulheres, assim se expressa: "Muitas mulheres provavelmente se alimentam do sadomasoquismo, do conforto proporcionado pelo marido no duplo sentido: financeirolafetivo"; mas quando prossegue em sua fala refere "a FALTA da casa, da comida, do conforto, do lazer, do sexo, sempre a falta". Aqui a informante destaca a questão da repartição da responsabilidade pela violência entre o homem agressor e a mulher agredida, além de destacar um "ganho secundário" da violência. Esse argumento do masoquismo é rechaçado pelas feministas e discutido no texto de Narvaz (2010). Esta autora argumenta que não existe um masoquismo específico das mulheres e descreve o contexto social que construiu essa ideia e se apresenta como "as condições de produção do discurso freudiano" (p. 52). Por outro lado, conclui dizendo: "O masoquismo, a passividade e o desejo de servidão sexual inscrevem-se, portanto, não numa pretensa natureza feminina, mas na história da produção ideológica das subjetividades em gêneros" (Narvaz, p. 55). Isso demonstra que, mesmo não sendo da ordem de uma pretensa natureza feminina por serem construídos ideologicamente, pode haver masoquismo, passividade e desejo de servidão sexual, apesar do questionamento da autora, a qual defende que existe, sim, uma produção ideológica desse masoquismo, mas que isso não o elimina enquanto possibilidade de vivência. $\mathrm{O}$ que a Informante 19 destacou e a
Informante 04 refere ainda nesse contexto é que as mulheres "acreditam merecer as atitudes do companheiro, (...) acreditam que este companheiro vai mudar, acreditam nas promessas que são feitas".

A dependência emocional também é identificada como algo que mantém as mulheres em situação de violência, e a informante 6 destaca essa dependência com o termo: "duplo vínculo", teoria que fundamentou o trabalho de Oliveira (2004) para explicar o fenômeno da violência doméstica não só a partir da categoria de análise gênero (Scott, 1990).

Os(as) informantes destacam ainda medo, vergonha, o tipo de personalidade, a não identificação da situação como violência, além dos modelos sociais e culturais, como afirma o informante 20: “(...) a ideologia predominantemente masculina, modelos familiares rigidamente tradicionais".

Por fim, os(as) participantes utilizam os mesmos argumentos do grupo que trabalha nos serviços especializados, com exceção do argumento sobre o "sadomasoquismo" e de uma corresponsabilização da mulher. Essas questões são criticadas pelas feministas por entenderem que discutir questões do desejo e do inconsciente, como fazem a psicanálise e a psicologia clínica de base analítica, seria culpar a mulher pela situação de violência e desconsiderar as bases sociais do fenômeno.

\section{CONSIDERAÇÕES FINAIS}

Nossa principal intenção ao fazer essa reflexão foi pensar que algo precisa ser feito para as mulheres que continuam em situações de violência mesmo após passar pelos serviços especializados. É preciso discutir a intervenção que tem de ser desenvolvida para esses casos. A defesa do princípio teórico-político da categoria Gênero (Scott, 1990) não pode ser mais importante que o sofrimento psíquico das mulheres submetidas à violência, destacado pelos(as) psicólogos(as) informantes como dependência emocional e "sadomasoquismo". Principalmente nos casos das mulheres que buscam os serviços especializados e continuam em situação de violência (Garcia et al., 2008), a intervenção psicológica faz-se necessária também para se trabalhar com os conteúdos da subjetividade (emoções, desejos inconscientes) e da individualidade, que favorecem atitudes de submissão à violência, juntamente com as questões de ordem cultural, uma vez que os(as) psicólogos(as), em sua atuação profissional, identificam a dificuldade das mulheres em revelar a violência sofrida e um sofrimento psíquico complexo presente nessa experiência. Não se está com isso dividindo 
subjetividade e cultura, pois não há com existir um sujeito sem uma cultura (Freud, 1921/2000,1930/2010). Dessa forma, não seria produtivo utilizar o argumento de que, ao pensarmos a subjetividade como ela é definida neste estudo, estaríamos negando as determinações sociais, histórias e culturais, e assim, justificando a negação da oportunidade de acompanhamento psicológico adequado à situação.

Pensar a política como se todas as mulheres vivessem a experiência de uma mesma forma ou que existe um único caminho para a superação é limitante. A psicologia tem um trabalho a oferecer para somar, contribuir no contexto da rede de enfrentamento à violência contra as mulheres. Não se avalia como produtiva uma equipe multiprofissional cujos integrantes precisem, todos, desenvolver a mesma atividade - a conscientização do papel de gênero como destacam as publicações da SPM (Brasil, 2003, 2005a e b, 2006). Pelo menos para um determinado grupo, a intervenção precisa ser mais específica, considerando os conteúdos inconscientes e identificando os sentidos ocultos da "escolha" de viver submetida à violência.

O trabalho da psicologia precisaria abordar os sentimentos e as dores das mulheres que vivenciam a ligação com um parceiro definida como dependência emocional, com culpa e vergonha por algo que sofrem, como se fossem elas que promovessem a situação e por isso a merecessem. Não se afirma que as mulheres sejam culpadas por apanhar, mas a forma como sentem a situação promove um sentimento de ser responsável construído a partir do lugar social atribuído ao feminino e vivido por algumas mulheres como algo que as aprisiona apesar de lhes serem apresentadas possíveis saídas. Talvez seja preciso discutir não a culpabilização das mulheres que continuam em relações mediadas pela violência, mas a corresponsabilização, que precisa ser considerada nesses casos. Dessa forma, essa pode ser uma possível intervenção da psicologia nos serviços especializados para o grupo de mulheres que, apesar das intervenções de empoderamento baseado nas teorias de gênero, continuam ligadas e vivenciando violências de todas as ordens.

Por fim, a proposta que se defende é pensar e entender a dinâmica da subjetividade de mulheres que se mantêm em relações mediadas pela violência, considerando inclusive a existência de masoquismo, passividade e desejo de servidão de algumas mulheres como uma construção política, ideológica e histórica. Por outro lado, independentemente de como é produzido o comportamento de se manter em relações violentas, faz-se necessário uma intervenção que aborde a dinâmica subjetiva - emoções e desejo - e assim se constitua um possível lugar de intervenção da psicologia clínica no contexto da violência contra as mulheres.

\section{REFERÊNCIAS}

Bardin, L. (1997). Análise de Conteúdo. Lisboa: Edições 70. (Original publicado em 1977).

Bastos, A. V. B., \& Gondim, S. M. G. (Orgs.), (2010). $O$ trabalho do psicólogo no Brasil. Porto Alegre: Artmed.

Bastos, A. V. B., Gondim, S. M. G., \& Rodrigues, A. C. A. (2010). Uma categoria profissional em expansão: quantos somos e onde estamos? In A. V. B. Bastos, \& S. M. G Gondim. (Orgs.), O trabalho do psicólogo no Brasil. (pp. 32-44). Porto Alegre: Artmed.

Brandão, E. R. (1998). Violência conjugal e o recurso feminino à polícia. In C. Bruschini, \& H. B. Hollanda (Orgs.), Horizontes plurais: novos estudos de gênero no Brasil. (pp. 51-84). São Paulo: Editora 34/Fundação Carlos Chagas.

Brasil, Presidência da República, Secretaria Especial de Políticas para as Mulheres. (2003). Programa de Prevenção, Assistência e Combate à Violência Contra a Mulher - Plano Nacional: diálogos sobre violência doméstica e de gênero: construindo políticas públicas. Brasília, DF: A Secretaria.

Brasil, Presidência da República, Secretaria Especial de Políticas para as Mulheres. (2005a). Termo de Referência Casa-abrigo. Portaria $\mathrm{n}^{\circ} .003$, de 24 de março.

Brasil, Presidência da República, Secretaria Especial de Políticas para as Mulheres. (2005b). Termo de Referência. Centro de referência e atendimento à mulher. Portaria $\mathrm{n}^{\circ}$ 003, de 24 de março.

Brasil, Presidência da República, Secretaria Especial de Políticas para as Mulheres. (2006). Norma Técnica de Uniformização: Centros de Referência de Atendimento à Mulher em Situação de Violência. Brasília, DF: A Secretaria.

Conselho Federal de Psicologia. (2007). Resolução $n^{o}$ 013/2007 de 14 de setembro de 2007 que Institui a Consolidação das Resoluções relativas ao Título Profissional de Especialista em Psicologia e dispõe sobre normas e procedimentos para seu registro. Brasília, DF: Autor.

Conselho Federal de Psicologia. (2008). Atuação de psicólogos em programas de atenção à mulher em situação de violência. (Relatório de pesquisa publicado no endereço eletrônico). Conselho Federal de Psicologia. Brasília, DF: CFP.

Conselho Federal de Psicologia. (2011). Resolução $n^{o}$ 005/2011 de 27 de fevereiro de 2011 que Cria o Conselho Regional de Psicologia da $20^{\mathrm{a}}$ Região, fixa novas jurisdições e dá outras providências. Brasília, DF: Autor.

D'Oliveira, A. F., \& Schraiber, L. B. (2000). Violência doméstica como problema para a saúde pública: Capacitação dos profissionais e estabelecimento de redes 
intersetoriais de reconhecimento, acolhimento e resposta ao problema. [CD-ROM] In VI Congresso Brasileiro de Saúde Coletiva, Salvador: Anais.

D'Oliveira, A. F. P. L., Schraiber L. B., França-Junior, I., Ludermir, A. B., Portella, A. P. Diniz, C. S., Couto, M. T., \& Valença, O. (2009). Fatores associados à violência por parceiro íntimo em mulheres brasileiras. Revista de Saúde Pública, 43 (2), 299-311.

Francisquetti, P. S. N. Saúde mental e violência: considerações acerca do atendimento em saúde mental a mulheres em situação de violência. Recuperado em 01 de maio, 2005, de http//www.mulheres.org.br/violência/documentos/saude_m ental_e_violencia.pdf

Freud, S. (2000). Psicologia de grupo e a análise do ego. (Edição Eletrônica Brasileira das Obras Psicológicas Completas de Sigmund Freud Volume XVIII). Rio de Janeiro: Imago. (Original publicado em 1921).

Freud, S. (2006). Luto e melancolia. (L. A. Hanns Coord. Geral Trad.). Escritos sobre a psicologia do inconsciente, volume II: 1915-1920. (pp.99-122). Rio de Janeiro: Imago. (Original publicado em 1917).

Freud, S. (2007). O problema econômico do masoquismo. (L. A. Hanns Coord. Geral Trad.). Escritos sobre a psicologia do inconsciente, volume III: 1923-1940. (pp.103-124). Rio de Janeiro: Imago. (Original publicado em 1924).

Freud, S. (2010). O mal-estar na cultura. (R. Zwick, Trad.) Porto Alegre, RS: L\&PM. (Original publicado em 1930).

Garcia, M. V., Ribeiro, L. A., Jorge, M. T., Pereira, G. R., \& Resende, A. P. (2008). Caracterização dos casos de violência contra a mulher atendidos em três serviços na cidade de Uberlândia, Minas Gerais, Brasil. Cadernos de Saúde Pública, 24 (11), 2551-2563.

Gondim, S. M. G., Luna, A. F., Souza, G. C., Sobral, L. C., \& Lima, M. S. (2010). A identidade do psicólogo brasileiro. In A. V. B. Bastos, \& S. M. G. Gondim. (Orgs.), $O$ trabalho do psicólogo no Brasil. (pp. 223-247). Porto Alegre: Artmed.

Hanada, H., D'Oliveira, A. F. P. L., \& Schraiber, L. B. (2008), Os psicólogos e a assistência a mulheres em situação de violência. In Fazendo Gênero 8 - Corpo, Violência $e$ Poder, Florianópolis.

Hanada, H., D'Oliveira, A. F. P. L., \& Schraiber, L. B. (2010). Os psicólogos na rede de assistência a mulheres em situação de violência. Revista de Estudos Feministas, 18 (1), 33-60.

Heise, L., Pitanguy, J., \& Germain, A. (1994). Violence Against Women: The Hidden Health Burden. Washington, DC: The International Bank for Reconstruction and Development/The World Bank.
Machado, C. (2004). Intervenção psicológica com vítimas de crimes: dilemas teóricos, técnicos e emocionais. International Journal of Clinical and Health Psychology, 4(2), 399-411.

Meneghel, S. N., Camargo, M., Fasolo, L. R., Mattiello, D. A., Silva, R. C. R. da, Santos, T. C. B., Dagord, A. L., Reck, A., Zanetti, L., Sottili, M., \& Teixeira, M. A. (2000). Mulheres cuidando de mulheres: um estudo sobre a Casa de Apoio Viva Maria, Porto Alegre, Rio Grande do Sul, Brasil. Porto Alegre, Rio Grande do Sul, Brasil. Cadernos de Saúde Pública, 16(3), 747-757.

Narvaz, M. G. (2010). Masoquismo feminino e violência doméstica: reflexões para a clínica e para o ensino da psicologia. Psicologia Ensino e Formação, 1(2), 47-59.

Oliveira, K. L. C. (2004). Quem tiver a garganta maior vai engolir o outro: sobre violências conjugais contemporâneas. São Paulo: Casa do Psicólogo.

Porto, M. (2006) Mulheres que cuidam de mulheres e as políticas de enfrentamento à violência contra a mulher. [CD-ROM] In Fazendo Gênero 7: gênero e preconceito. Florianópolis.

Porto, M. (2008) Intervenção Psicológica em Abrigo para Mulheres em Situação de Violência: uma Experiência. Psicologia: Teoria e Pesquisa, 24(3), 369-374.

Prado Filho, K., \& Martins, S. (2007) A subjetividade como objeto da(s) psicologia(s). Psicologia \&. Sociedade, 19(3), 14-19.

Schraiber, L. B., D’Oliveira, A. F. P. L., Couto, M. T., Hanada, H., Kiss, L. B., Durand, J. G., Puccia, M. I., \& Andrade, M. C. (2007). Violência contra mulheres entre usuárias de serviços públicos de saúde da Grande São Paulo. Revista de Saúde Pública, 41 (3), 359-367.

Scott, J. (1990). Gênero: uma categoria útil de análise histórica. Educação e Realidade, 16(2), 5-22.

Seymour, W. S. (2001) In the flesh or online? Exploring qualitative research methodologies. Qualitative Research, I(2), 147-168.

Recebido em 01/09/2011 Aceito em 12/06/2012
Endereço para correspondência:

Madge Porto. Universidade Federal do Acre. Pró-Reitoria de Desenvolvimento e Gestão de Pessoas. BR 364, Km04, Distrito Industrial, CEP 69920-900, Rio Branco-AC, Brasil. E-mail: madgeporto@gmail.com. 